\title{
NGHIÊN CỨU TÍNH TOÁN PHÂN VÙNG HẠN - MặN VÙNG ĐỒNG BĂNG VEN BIỂN SÔNG MÃ TRONG ĐIỀU KIỆN BIẾN ĐỒI KHÍ HậU
}

\section{Lê Thị Thường ${ }^{1}$}

Tóm tắt: Vùng đồng bằng ven biển sông Mã chịu ảnh huởng nặng nề của hạn hán, xâm nhập mặn, đặc biệt trong bối cảnh biến đổi khí hậu hiện nay, mưc độ ảnh hưởng càng nghiêm trọng hơn. Hạn hán và xâm nhập mặn thường có quan hệ đồng thời nhưng ảnh hưởng của nó được thể hiện khác nhau ở nhũ̃ng tiểu vùng khác nhau trong cùng một khu vực nghiên cứu. Chính vì vậy, để giảm thiểu đến mức tối đa nhũng tác hại do hạn - mặn gây ra cần phân vùng hạn - mặn thành các tiểu vùng làm cơ sở đề xuất các giải pháp sủ dụng nước phù hợp. Bài báo sủ dụng bộ mô hình Mike (Mike Nam và Mike 11) để tính toán dòng chảy đến hồ chứa tù mura theo biến đổi khí hậu và mô phỏng thủy lục mạng sông khu vực nghiên cưu xét trong mối quan hệ hạn - mặn. Nghiên cứu đã chỉ ra được 03 tiểu vùng hạn - mặn tuoong ứng với nồng độ mặn khác nhau. Kết quả này có ý nghĩa trong việc giúp nhà quản lý cũng như người dân chủ động trong việc chuyển đổi co cấu cây trồng vật nuôi sao cho phù hợp nhất.

Từ khóa: Hạn - mặn, vùng đồng bằng ven biển sông Mã, biến đổi khi hậu.

Ban Biên tập nhận bài: 25/11/2018 Ngày phản biện xong: 20/01/2019 Ngày đăng bài: 25/03/2019

\section{Mở đầu}

Vùng đồng bằng ven biển sông Mã là khu vực có tốc độ phát triển kinh tế cao theo xu hướng chuyển dịch cơ cấu kinh tế và chuyển đổi cơ cấu cây trồng. Vì vậy, nhu cầu sử dụng nước và giảm thiểu tác động bất lợi do nước gây ra luôn được đặt ra. Vùng ven biển sông Mã bao gồm các huyện: Nga Sơn, Hậu Lộc, Hoàng Hóa, TP Sầm Sơn, Quảng Xương cùng với mạng lưới sông ngòi đổ ra biển qua các cửa sông: Cửa Hới, Lạch Sung, Lạch Trường (hình 1). Về mùa cạn, khi lượng dòng chảy từ thượng nguồn giảm mạnh kết hợp với mực nước tại các trạm hạ lưu bị hạ thấp so với trung bình nhiều năm khi đó xâm nhặp mặn có cơ hội tiến sâu vào trong sông. Đặc biệt trong bối cảnh biến đổi khí hậu thì mối quan hệ giữa hạn hán và xâm nhập mặn càng thể hiện rõ: ảnh hưởng bất lợi của biến đổi khí hậu càng nhiều thì hạn hán càng tăng, mặn càng tiến sâu vào trong sông, gây thiệt hại không nhỏ trong sản xuất nông nghiệp, nuôi trồng thủy hải sản ở vùng ven biển. Chính vì vậy cũng có rất nhiều nghiên cứu về hạn hán, xâm nhập mặn vùng ven

${ }^{1} Đ a ̣ i$ học Tài nguyên và Môi trường Hà Nội Email:ltthuong.kttv@hunre.edu.vn biển nói chung và ven biển sông Mã nói riêng, tiêu biểu như:

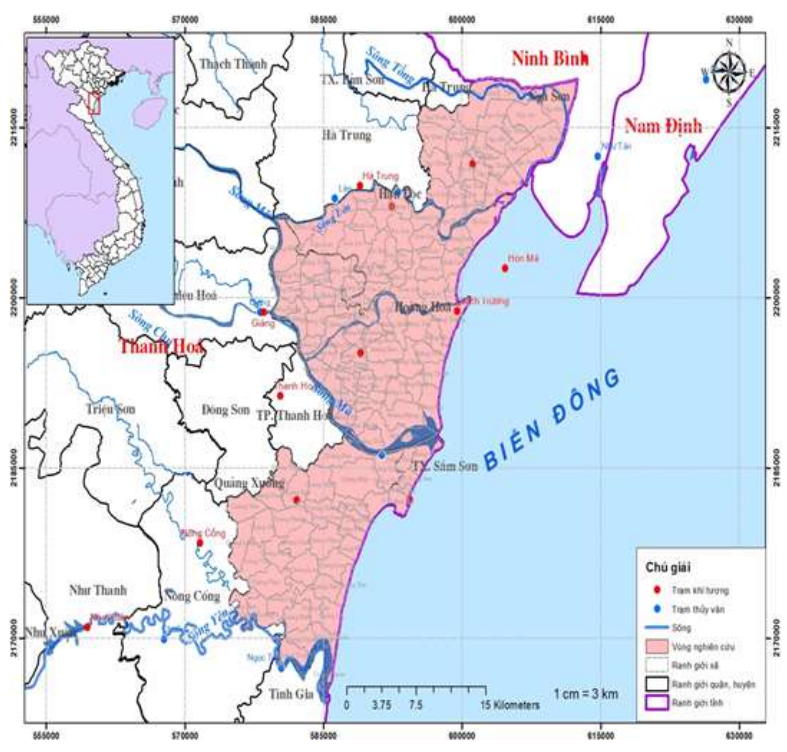

Hình 1. Phạm vi khu vục nghiên cứu

Đề tài cấp Nhà nước của PGS.TS Nguyễn Quang Trung - Viện Nước, Tưới tiêu và Môi trường làm chủ nhiệm: "Nghiên cứu đề xuất các giải pháp giảm thiểu ảnh hưởng của dòng chảy kiệt phục vụ sản xuất nông nghiệp, thủy sản vùng hạ du sông Cả và sông Mã” đã đánh giá được nguyên nhân cũng như tình hình hiện trạng 
hạn hán, xâm nhập mặn vùng hạ lưu sông Cả và sông Mã, các tác động của hạn hán đến sản xuất nông nghiệp, thủy sản và đời sống kinh tế xã hội, tính toán cân bằng nước và xây dựng được bản đồ hạn cho hai lưu vực, đề xuất giải pháp phục vụ sản xuất nông nghiệp và thủy sản vùng hạ du sông Cả và sông Mã [6]. Tuy nhiên nghiên cứu chưa tính toán phân vùng hạn - mặn cũng như chưa xét đến điều kiện biến đổi khí hậu.

Các nghiên cứu "Xây dựng mô hình dự báo xâm nhập mặn vùng hạ lưu sông Mã, sông Yên tỉnh Thanh Hóa" của Lã Thanh Hà (2014) [1] đã đánh giá được thực trạng xâm nhập triều, mặn khu vực sồng bằng sông Hồng - Thái Bình, sông Mã; xây dựng cơ sở dữ liệu và công nghệ dự báo xâm nhập mặn và chương trình dự báo xâm nhập mặn cho lưu vực sông Mã; Trần Hồng Thái và Đoàn Quang Trí (2017) trong nghiên cứu [4] đã sử dụng kết hợp mô hình 1 chiều (Mike 11) và mô hình 2 chiều (Mike 21) mô phỏng quá trình xâm nhập mặn cũng như đưa ra các kịch bản xâm nhập mặn xét trong điều kiện mùa cạn với các tần suất dòng chảy $75 \%, 90 \%$ và 95\%. Tuy nhiên, nghiên cứu chưa phân vùng hạn - mặn cũng như chưa đánh giá ảnh hưởng của biến đổi khí hậu (kịch bản BĐKH 2016) đến bài toán phân vùng hạn - mặn. Vì vậy, mục đích của nghiên cứu này là: (i) Ứng dụng mô hình Mike Nam diễn toán dòng chảy đến hồ chứa làm biên đầu vào cho mô hình Mike 11 (ii) Xây dựng bản đồ phân vùng hạn - mặn theo chức năng từng đoạn sông tương ứng với các kịch bản biến đổi khí hậu. Đây đang là một hướng nghiên cứu mới nhằm giảm thiểu tối đa tác hại do hạn hán, xâm nhập mặn gây ra.

\section{liệu}

2. Phương pháp nghiên cứu và thu thập dữ

Để thực hiện được mục tiêu nghiên cứu, mô hình MIKE 11 được áp dụng để mô phỏng, hiệu chỉnh và kiểm định thủy lực và khuếch tán mặn. Thêm vào đó, các kịch bản trong tương lai được đưa ra để cảnh báo xâm nhập mặn khu vực hạ lưu dưới tác động của biến đổi khí hậu cũng được xem xét bằng việc sử dụng MIKE - NAM tính dòng chảy từ mưa theo biến đổi khí hậu, từ đó làm cơ sở đầu vào cho biên trên của mô hình thủy lực MIKE 11 (hình 2).

\subsection{Cơ sở lý thuyết mô hình Mike - Nam}

Là một mô đun mưa rào - dòng chảy được tích hợp trong mô hình MIKE 11 được sử dụng để dự báo dòng chảy, tính lượng gia nhập khu giữa...Các thông số của mô hình như: Lmax, Qmax, CQOF, TOF, TIF, TG... Nghiên cứu đã sử dụng số liệu mưa giờ giai đoạn (1986 - 2005) của 14 trạm mưa trong khu vực nghiên cứu và khu vực lân cận, bao gồm: Cẩm Thủy, Xã Là, Mai Châu, Thạch Quảng, Hồi Xuân, Yên Châu, Tuần Giáo, Pha Đin, Sông Mã, Sơn La, Tuần Giáo, Bát Mọt, Cửa Đạt. Sử dụng phần mềm Mapinfo và bản đồ số hóa, chia lưu vực nghiên cứu (tính từ thượng lưu đến Cẩm Thủy (sông Mã) và trạm Cửa Đạt trên sông Chu) thành 4 lưu vực bộ phận với diện tích phân bố và các tỷ lệ diện tích thành phần (hình $3 \mathrm{a}$ ), bản đồ xác trọng số các tiểu lưu vực (hình $3 b$ ).

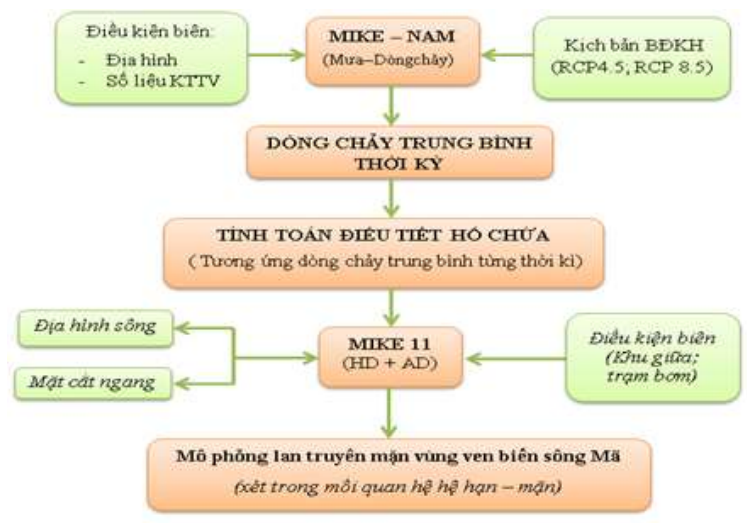

Hình 2. So đồ áp dụng mô hình toán mô phỏng hạn - mặn vùng đồng bằng ven biển sông Mã

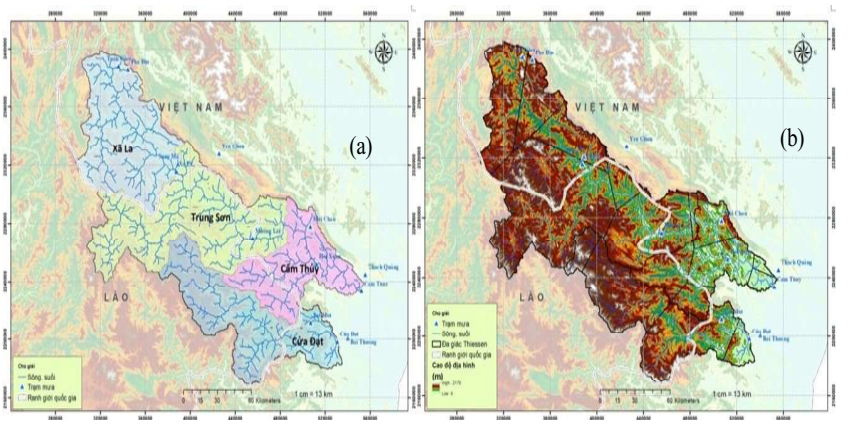

Hình 3. Bản đồ phân chia các luu vục bộ phận (a); Bản đồ xác định trọng số các tiểu lưu vực theo đa giác Thiessen (b) 


\subsection{Co' sở lý thuyết mô hình MIKE 11}

Phương trình cơ bản của MIKE 11 là phương trình liên tục và phương trình động lượng (hệ phương trình Saint Venant).

Phương trình liên tục:

$$
\frac{\partial Q}{\partial x}+\frac{\partial A}{\partial t}=q
$$

Phương trình động lượng:

$$
\frac{\partial Q}{\partial t}+\frac{\partial\left(\propto \frac{Q^{2}}{A}\right)}{\partial x}+g A \frac{\partial h}{\partial x}+\frac{g Q|Q|}{C^{2} A R}=0
$$

Trong đó: $\mathrm{Q}$ là lưu lượng $\left(\mathrm{m}^{3} / \mathrm{s}\right)$; A là diện tích mặt cắt ngang $\left(\mathrm{m}^{2}\right)$; q là lưu lượng nhập lưu trên 1 đơn vị chiều dài dọc sông $\left(\mathrm{m}^{2} / \mathrm{s}\right)$; C là hệ số Chezy, $C=\frac{1}{n} R^{y}$, theo Manning $\mathrm{y}=1 / 6 ; \alpha$ là hệ số sửa chữa động lượng; R: bán kính thủy lực $(\mathrm{m})$; $\mathrm{g}$ là gia tốc trọng trường $\left(\mathrm{m} / \mathrm{s}^{2}\right)$; h là độ sâu dòng nước $(\mathrm{m})$; $\mathrm{x}$ là biến không gian.

Nghiên cứu sử dụng Mike 11 để mô phỏng hạn - mặn có xét đến hồ chứa trong điều kiện biến đổi khí hậu, tính toán cho hai thời kì (2016 - 2035) và (2045 - 2065). Ở đây, nghiên cứu đưa vào hai hồ chứa có công suất lớn điển hình: hồ Cửa Đạt (sông Chu) và hồ Trung Sơn (sông Mã). Các bước tính toán thể hiện và phạm vi mô phỏng như hình $4(a, b)$.

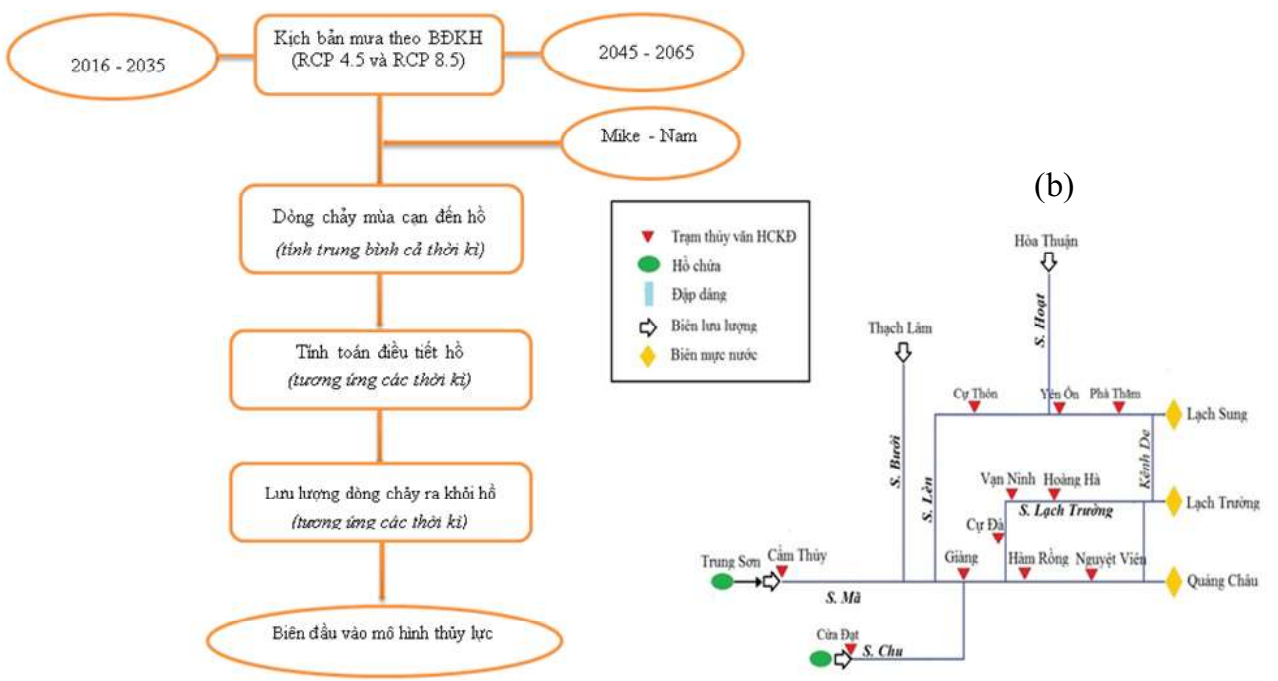

Hình 3. (a) So đồ các bước tính toán biên trên mô hình Mike 11; (b)So đồ mô phỏng mang luói sông trong Mike 11 kịch bản BĐKH

Nghiên cứu sử dụng số liệu mưa giờ tại các trạm mưa thời kì nền (1986 - 2005), sau đó dựa vào sự biến đổi lượng mưa theo các kịch bản RCP 4.5 và $\mathrm{RCP} 8.5$ [3], tính được lương mưa theo các kịch bản BĐKH cho các thời kỳ (20162035) và (2045 - 2065).

Theo đó mô hình Mike - Nam được sử dung để tính dòng chảy đến hồ từ mưa, sau đó tính toán điều tiết qua hồ chứa theo phương pháp lập bảng. Trong đó, lượng nước dùng trong trong tương lai (kịch bản biến đổi khí hậu) tăng 10.3\% so với thời kỳ hiện trạng. Tỷ lệ này tham khảo theo [7]. Lượng nước xả xuống hạ lưu sẽ được xác định bằng tổng lượng nước xả qua nhà máy thủy điện và lượng xả thừa (có kể đến tổn thất thấm và bốc hơi). Tổn thất bao gồm thấm và bốc hơi (lượng tổn thất thấm được tính theo lưu lượng thấm trung bình từ số liệu đo đạc thực tế tại hồ; lượng tổn thất bốc hơi được tính theo diện tích mặt thoáng hồ và lượng bốc hơi (được tính theo số liệu bốc hơi trung bình nhiều năm tại trạm khí tượng Bái Thượng). Quá trình tính toán điều tiết có tham khảo mực nước tối thiểu của các hồ chứa được quy định tại [3].

Theo hình 3b: (1) biên trên: Lưu lượng ra khỏi hồ Cửa Đạt, hồ Trung Sơn thông qua quá trình tính toán điều tiết hồ tính trung bình thời kì ứng với từng kịch bản; (2) Biên dưới: Số liệu mực nước giờ thời kì (1986 - 2005) quan trắc tại các trạm: Quảng Châu (sông Mã), Lạch Trường (cửa sông Lạch Trường), Lạch Sung (cửa sông Lèn) và căn cứ vào sự gia tăng mực nước của các 


\section{BÀI BÁO KHOA HỌC}

thời kì đối với từng loại kịch bản. Biên mặn: Với các biên trên thì coi độ mặn bằng không, độ mặn tại cửa Hới, cửa Lạch Trường và cửa Lạch Sung được giả định trong tương lai là không đổi so với thời kì hiện trạng; (3) Điều kiện hệ thống: Trong nghiên cứu đưa vào mô phỏng hệ thống các trạm bơm điển hình dọc sông có công suất lớn theo số liệu của Công ty TNHH một thành viên thủy lợi Nam sông Chu, Bắc sông Mã "Báo cáo tổng hợp các chỉ tiêu kỹ thuật của các trạm bơm” (2018). Trường hợp này giả sử trong tương lai công suất trạm bơm không thay đổi so với hiện trạng.

\section{Kết quả nghiên cứu}

\subsection{Hiệu chỉnh và kiểm định mô hình}

3.1.1 Mô hình Mike - Nam: Nghiên cứu đã tiến hành mô phỏng, hiệu chỉnh dựa trên tập số liệu lưu lượng giờ giai đoạn (1996 - 2000) tại các trạm Xã Là, Cửa Đạt, Cẩm Thủy. Kết quả thu được đường quá trình dòng chảy tính toán và thực đo (hình $4 \mathrm{a}, 4 \mathrm{~b}$ ); Tiêu chí đánh giá chất lượng hiệu chỉnh (bảng 1).
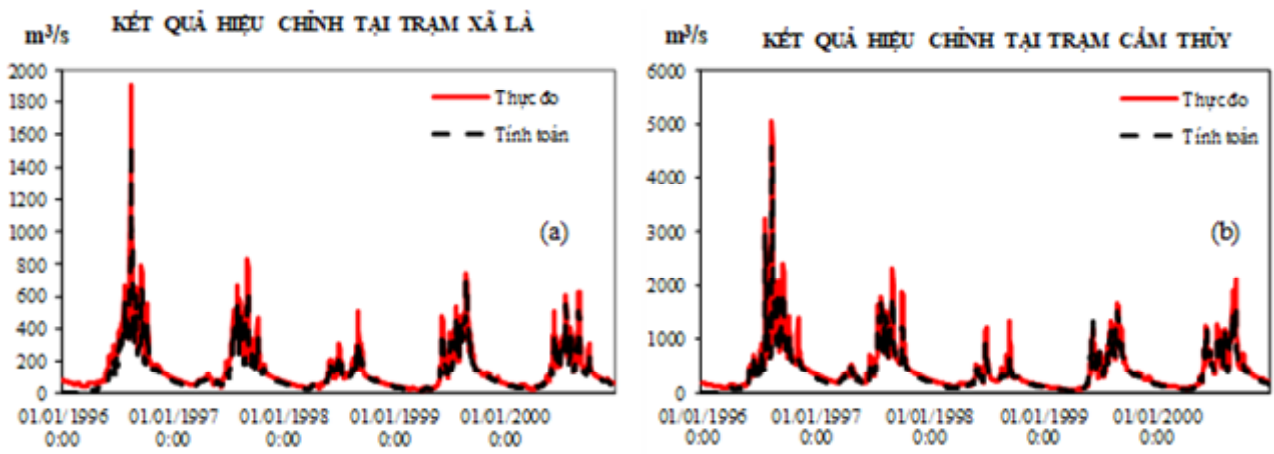

Hình 4. Đưòng quá trình dòng chảy tính toán và thực đo hiệu chỉnh trạm Xã Là (a); trạm Cẩm Thủy (b)

Bảng 1. Chỉ tiêu đánh giá chất lượng hiệu chỉnh

\begin{tabular}{cccl}
\hline $\begin{array}{c}\text { Trạm } \\
\text { hiệu chỉnh }\end{array}$ & Chỉ tiêu Nash & Sai số đỉnh & Ghi chú \\
\hline Xã Là & 0.79 & 0.048 & Đạt yêu cầu \\
Cẩm Thủy & 0.87 & -0.035 & Đạt yêu cầu \\
Cửa Đạt & 0.82 & 0.028 & Đạt yêu cầu \\
\hline
\end{tabular}

Kết quả hiệu chỉnh mô hình cho thấy, mô Nash đạt từ 0,79 đến 0,82 . Bộ thông số tìm được hình mô phỏng cho kết quả đạt yêu cầu, chỉ tiêu sau quá trình hiệu chỉnh (bảng 2).

Bảng 2. Bộ thông số của mô hình MIKE - NAM

\begin{tabular}{cccccccccc}
\hline $\begin{array}{c}\text { Tiểu lưu } \\
\text { vực }\end{array}$ & $\mathrm{U}_{\max }$ & $\mathrm{L}_{\max }$ & $\mathrm{CQOF}$ & $\mathrm{CK}_{\mathrm{IF}}$ & $\mathrm{CK}_{1,2}$ & $\mathrm{~T}_{\mathrm{OF}}$ & $\mathrm{T}_{\mathrm{IF}}$ & $\mathrm{T}_{\mathrm{G}}$ & $\mathrm{CK}_{\mathrm{BF}}$ \\
\hline Cẩm Thủy & 10,60 & 108,00 & 0,41 & 329,90 & 34,10 & 0,68 & 0,26 & 0,026 & 2098 \\
Xã Là & 10,98 & 199,22 & 0,56 & 557,60 & 37,03 & 0,71 & 0,20 & 0,021 & 2213 \\
Cửa Đạt & 16,52 & 259,00 & 0,29 & 553,10 & 23,57 & 0,05 & 0,15 & 0,031 & 1792 \\
Trung Sơn & 18,60 & 210,00 & 0,45 & 574,80 & 39,80 & 0,59 & 0,18 & 0,268 & 2659 \\
\hline
\end{tabular}

Kiểm định mô hình

Sau khi hiệu chỉnh thu được bộ thông, nghiên cứu tiến hành kiểm định bộ thông số bằng tập số liệu độc lập. Kết quả thu được thể hiện như hình $5(\mathrm{a}, \mathrm{b})$ và bảng 3 . 

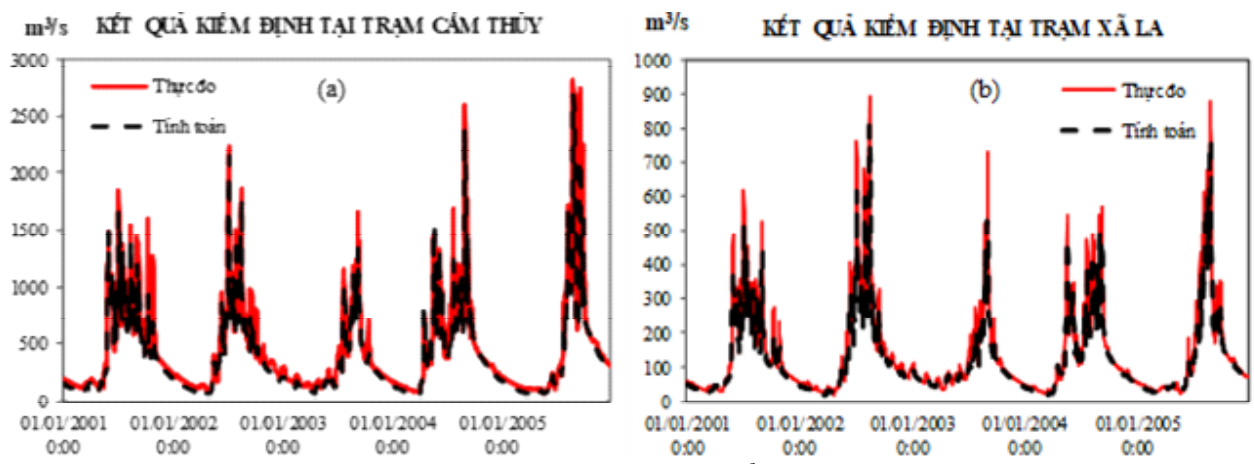

Hình 5. Đuò̀ng quá trình dòng chảy tính toán và thục đo kiểm định trạm Cửa Đạt (a), trạm Cẩm Thủy (b)

Bảng 3. Chỉ tiêu đánh giá chất lương kiểm định

\begin{tabular}{cccc}
\hline Trạm hiệu chỉnh & Chỉ tiêu Nash & Sai số đỉnh & Ghi chú \\
\hline Xã Là & 0.71 & -0.026 & Đạt yêu cầu \\
Cẩm Thủy & 0.82 & 0.049 & Đạt yêu cầu \\
Cửa Đạt & 0.78 & 0.030 & Đạt yêu cầu \\
\hline
\end{tabular}

Bộ thông số mô hình Mike - Nam đã được kiểm định và hiệu chỉnh đạt yêu cầu với chỉ tiêu Nash đạt từ 0,71 đến 0,87 , sai số đỉnh nhỏ hơn $10 \%$. Do vậy có thể sử dụng để tính dòng chảy đến hồ từ mưa, phục vụ tính toán điều tiết hồ.

3.1.2 Mô hình Mike 11: Kết quả kiểm định và hiệu chỉnh mô hình Mike 11, mô đun $H D$ và $A D$ được kế thừa từ nghiên cứu [5].

\subsection{Kết quả mô phỏng ranh giới hạn - mặn hợp từ kết quả mô phỏng và ArcGIS).} vùng đồng bằng ven biển sông Mã.

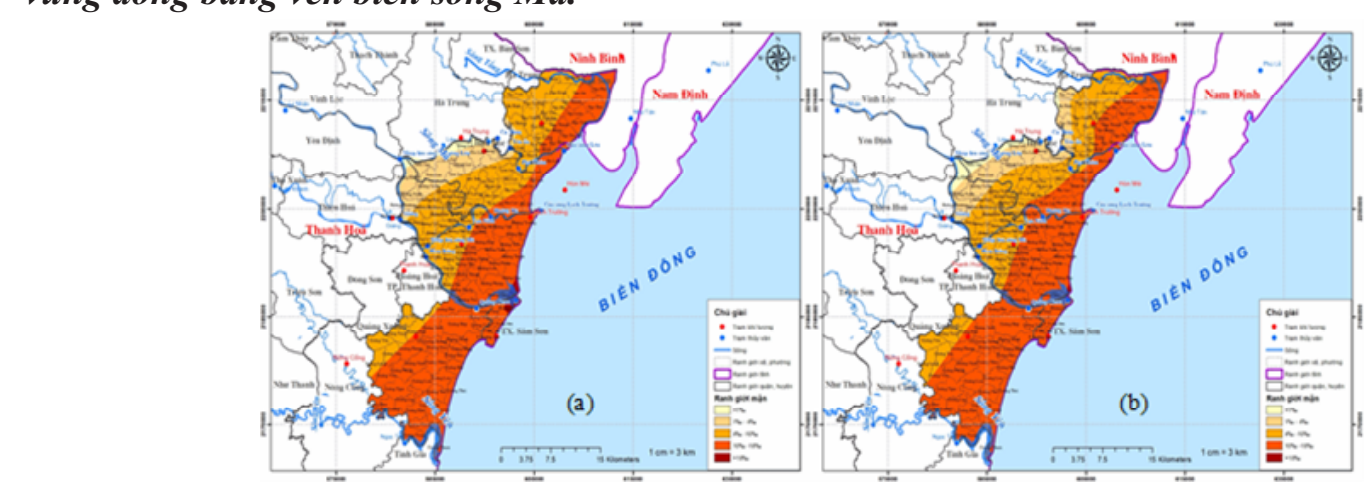

Mối quan hệ hạn - mặn được thể hiện trong mô hình mô phỏng với biên trên là lượng nước ra khỏi hồ tính trong thời kì kiệt nhất (2/IV - 16/IV); biên dưới là mực nước và độ mặn tương ứng. Kết quả mô phỏng mối quan hệ hạn - mặn tương ứng với các trường hợp được thể hiện như hình $6(\mathrm{a}, \mathrm{b})$ và hình $7(\mathrm{a}, \mathrm{b})$. Đây là ranh giới hạn - mặn tiềm năng giả thiết được xây dựng theo quá trình nội suy (kết

Hình 6. Kết quả mô phỏng hạn - mặn kịch bản RCP 4.5 thời kì 2016-2035 (a) và kịch bản RCP 8.5 thời kì $2016-2035$ (b)

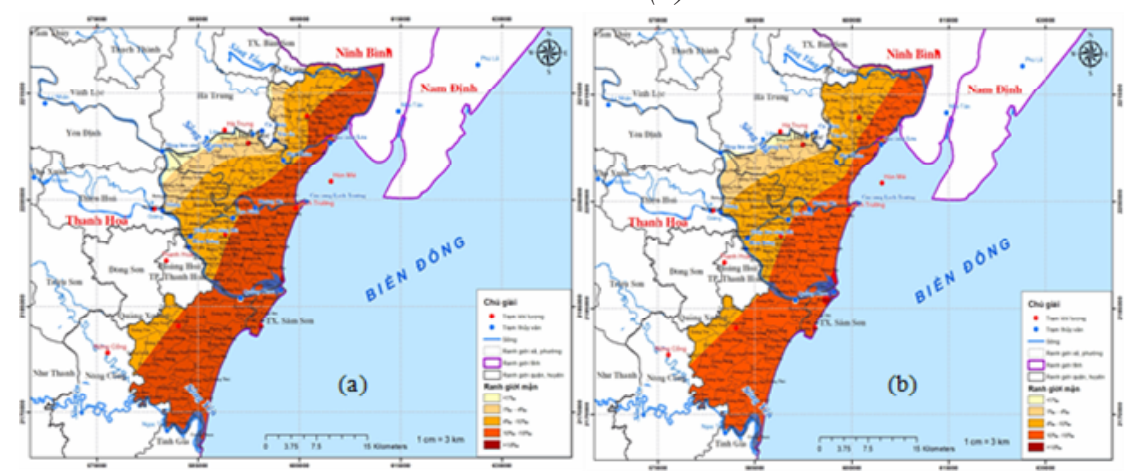

Hình 7. Kết quả mô phỏng hạn - mặn kịch bản RCP 4.5 thời kì 2046-2065 (a) vàkịch bản RCP 8.5 thòi kì $2046-2065(b)$ 


\section{BÀI BÁO KHOA HỌC}

Từ quá trình mô phỏng hạn - mặn theo kịch bản biến đổi khí hậu cho thấy: Trong thời kỳ 2016 - 2035 với kịch bản RCP 8.5 mặn tiến sâu hơn vào trong sông so với RCP 4.5. Ví như trên sông Mã với khoảng dao động của độ mặn từ $10 \%$ đến $18 \%$ thì quá trình mô phỏng hạn - mặn theo kịch bản RCP 8.5 vào sâu đến vị trí xã Quảng Phú (cách cửa Hới 11,8km), trong khi kịch bản RCP 4.5 chỉ vào sâu đến vị trí xã Hoằng Đại (cách cửa Hới $10 \mathrm{~km}$ ). Trên sông Lạch Trường, với kịch bản RCP 8.5 vào sâu đến xã Hoàng Đạt (cách cửa Lạch Trường 12,4km), với kịch bản RCP 4.5, cùng độ mặn nhưng chỉ xâm nhập sâu vào đến vị trí xã Hoằng Hà (cách cửa Lạch Trường 11,2km). Sở dĩ như vậy bởi đối với kịch bản RCP8.5 lượng dòng chảy xuống hạ lưu sau khi tính điều tiết hồ nhỏ hơn so với trường hợp RCP4.5 nên mặn xâm nhập vào sâu sơn. Cụ thể, kịch bản RCP 8.5 tại Trung Sơn (sông Mã) là $78.7 \mathrm{~m}^{3} / \mathrm{s}$, Cửa Đạt (sông Chu) là $64.2 \mathrm{~m}^{3} / \mathrm{s}$, trong khi đó với kịch bản RCP 4.5 tại Trung Sơn (sông Mã) là $90.6 \mathrm{~m}^{3} / \mathrm{s}$, Cửa Đạt (sông Chu) là $76.4 \mathrm{~m}^{3} / \mathrm{s}$. Đồng thời mực nước biên dưới ở cả hai kịch bản RCP 4.5 và RCP 8.5 đều tăng $13 \mathrm{~cm}$.

\subsection{Phân vùng hạn - mặn theo chức năng tù̀ng đoạn sông}

Căn cứ theo kết quả mô phỏng hạn - mặn từ mô hình xét trong mối quan hệ hạn - mặn với điều kiện có xét đến ảnh hưởng của hồ chứa trong bối cảnh biến đổi khí hậu và tính trung bình cho cả thời kì (2016 - 2035) và (2045 2065) nghiên cứu lấy giá trị độ mặn lớn nhất (bảng 4). Từ đó, sử dụng kết quả này kết hợp với ArcGIS để phân vùng hạn - mặn theo chức năng từng đoạn sông ứng từng thời kì (hình $8(\mathrm{a}, \mathrm{b}))$.

Bảng 4. Giá trị độ mặn lớn nhất kịch bản biến đổi khỉ hậu

\begin{tabular}{|c|c|c|c|c|c|c|}
\hline \multirow[b]{2}{*}{ Sông } & \multirow[b]{2}{*}{ Vị trí quan trắc } & \multirow{2}{*}{$\begin{array}{l}\text { Khoảng } \\
\text { cách đến } \\
\text { biển }(\mathrm{km})\end{array}$} & \multicolumn{2}{|c|}{ 2016-2035 } & \multicolumn{2}{|c|}{$2046-2065$} \\
\hline & & & $\begin{array}{c}\text { RCP } 4.5 \\
(\%)\end{array}$ & $\begin{array}{c}\mathrm{RCP} 8.5 \\
(\%)\end{array}$ & $\begin{array}{c}\text { RCP } 4.5 \\
(\% \circ)\end{array}$ & $\begin{array}{c}\mathrm{RCP} 8.5 \\
(\%)\end{array}$ \\
\hline \multirow{3}{*}{$\begin{array}{c}\text { Sông } \\
\text { Mã }\end{array}$} & Quảng Châu & 6.0 & 13.78 & 13.90 & 13.9 & 14.1 \\
\hline & Hàm Rồng & 18.5 & 5.87 & 6.18 & 6.30 & 6.38 \\
\hline & Giàng & 23.0 & 3.62 & 3.90 & 4.10 & 4.24 \\
\hline Sông & Hoàng Hà & 11.2 & 11.47 & 11.58 & 11.6 & 11.6 \\
\hline Lạch & Vạn Ninh & 18.0 & 9.42 & 9.48 & 9.48 & 9.50 \\
\hline Trường & Nhập lưu sông Mã & 22.0 & 5.87 & 6.19 & 6.29 & 6.30 \\
\hline \multirow{3}{*}{$\begin{array}{c}\text { Sông } \\
\text { Lèn }\end{array}$} & Phà Thắm & 9.0 & 5.88 & 5.95 & 5.80 & 5.90 \\
\hline & Cụ Thôn & 18.0 & 2.71 & 2.76 & 1.05 & 1.05 \\
\hline & Nhập lưu sông Mã & 40.0 & 0.22 & 0.26 & 0.23 & 0.23 \\
\hline
\end{tabular}

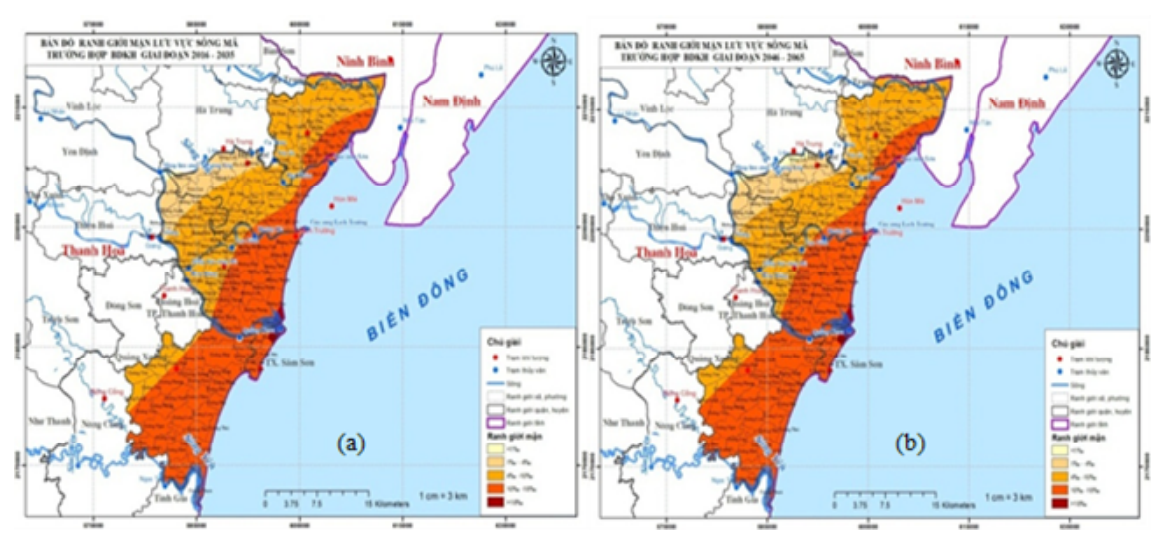

Hình 8. Bản đồ phân vùng hạn - mặn theo chức năng tùng đoạn sông thời kì 2016-2035 (a); thời ki 2046 - 2065 (b) 
Ở khu vực đồng bằng cửa sông giáp biển thì xâm nhập mặn là quá trình tự nhiên, kết hợp với nghiên cứu phân thành 3 vùng chịu ảnh hưởng kết quả mô phỏng mối quan hệ hạn - mặn,

Bảng 5. Phân vùng hạn - mặn theo chức năng tùng đoạn sông thời kì (2016 - 2035)

\begin{tabular}{|c|c|c|c|c|c|}
\hline \multirow{2}{*}{$\begin{array}{l}\text { Phân } \\
\text { vùng }\end{array}$} & \multirow{2}{*}{$\begin{array}{l}\text { Giới hạn đoạn sông } \\
\text { tương ứng }\end{array}$} & \multirow[t]{2}{*}{ Sông } & \multicolumn{2}{|c|}{$\begin{array}{c}\text { Khoảng dao động độ mặn } \\
(\%)\end{array}$} & \multirow{2}{*}{$\begin{array}{c}\text { Mức độ } \\
\text { nhiễm mặn }\end{array}$} \\
\hline & & & $\mathrm{RCP} 4.5$ & RCP8.5 & \\
\hline \multirow{3}{*}{ Vùng 1} & Cửa Hới - Quảng Châu & Mã & $19.5-13.7$ & $19.5-13.9$ & \multirow{3}{*}{$\begin{array}{l}\text { Hoàn toàn bị } \\
\text { nhiễm mặn }\end{array}$} \\
\hline & Cửa L.Trường - Hoàng Hà & L.Trường & $16.3-11.47$ & $16.3-11.58$ & \\
\hline & Cửa L. Sung - Phà Thắm & Lèn & $15.4-5.88$ & $15.4-5.95$ & \\
\hline \multirow{3}{*}{ Vùng 2} & Quảng Châu - Hàm Rồng & Mã & $13.7-5.87$ & $13.9-6.18$ & \multirow{3}{*}{$\begin{array}{l}\text { Ảnh hưởng } \\
\text { thường xuyên } \\
\text { trong mùa cạn }\end{array}$} \\
\hline & Hoàng Hà - Vạn Ninh & L.Trường & $11.47-9.42$ & $11.58-9.48$ & \\
\hline & Phà Thắm - Cụ Thôn & Lèn & $5.88-2.71$ & $5.95-2.76$ & \\
\hline \multirow{3}{*}{ Vùng 3} & Hàm Rồng - Giàng & Mã & $5.87-3.62$ & $6.18-3.90$ & \multirow{3}{*}{$\begin{array}{l}\text { Ảnh hưởng } \\
\text { yếu và không } \\
\text { thường xuyên }\end{array}$} \\
\hline & Vạn Ninh - Ngã ba Tuần & L.Trường & $9.42-5.85$ & $9.48-6.15$ & \\
\hline & Cụ Thôn - Ngã ba Bông & Lèn & $2.71-0.22$ & $2.76-0.26$ & \\
\hline
\end{tabular}

Bảng 6. Phân vùng hạn - mặn theo chức năng tùng đoạn sông thời kì (2046 - 2065)

\begin{tabular}{|c|c|c|c|c|c|}
\hline \multirow{2}{*}{$\begin{array}{l}\text { Phân } \\
\text { vùng }\end{array}$} & \multirow{2}{*}{$\begin{array}{l}\text { Giới hạn đoạn sông } \\
\text { tương ứng }\end{array}$} & \multirow[t]{2}{*}{ Sông } & \multicolumn{2}{|c|}{$\begin{array}{l}\text { Khoảng dao động độ mặn } \\
\text { (\%o) }\end{array}$} & \multirow{2}{*}{$\begin{array}{c}\text { Mức độ } \\
\text { nhiễm mặn }\end{array}$} \\
\hline & & & $\mathrm{RCP} 4.5$ & RCP8.5 & \\
\hline \multirow{3}{*}{ Vùng 1} & Cửa Hới - Quảng Châu & Mã & $19.5-13.9$ & $19.5-14.1$ & \multirow{3}{*}{$\begin{array}{l}\text { Hoàn toàn bị } \\
\text { nhiễm mặn }\end{array}$} \\
\hline & Cửa L.Trường - Hoàng Hà & L.Trường & $16.3-11.59$ & $16.3-11.6$ & \\
\hline & Cửa L.Sung - Phà Thắm & Lèn & $15.4-5.80$ & $15.4-5.90$ & \\
\hline \multirow{3}{*}{ Vùng 2} & Quảng Châu - Hàm Rồng & Mã & $13.9-6.30$ & $13.9-6.38$ & \multirow{3}{*}{$\begin{array}{l}\text { Ảnh hưởng } \\
\text { thường xuyên } \\
\text { trong mùa cạn }\end{array}$} \\
\hline & Hoàng Hà - Vạn Ninh & L.Trường & $11.59-9.48$ & $11.60-9.50$ & \\
\hline & Phà Thắm - Cụ Thôn & Lèn & $5.80-1.03$ & $5.90-1.05$ & \\
\hline \multirow{3}{*}{ Vùng 3} & Hàm Rồng - Giàng & Mã & $6.30-4.10$ & $6.38-4.25$ & \multirow{3}{*}{$\begin{array}{l}\text { Ảnh hưởng } \\
\text { yếu và không } \\
\text { thường xuyên }\end{array}$} \\
\hline & Vạn Ninh - Ngã ba Tuần & L.Trường & $9.48-6.20$ & $9.50-6.30$ & \\
\hline & Cụ Thôn - Ngã ba Bông & Lèn & $1.03-0.22$ & $1.05-0.22$ & \\
\hline
\end{tabular}

Nhận xét: Từ kết quả tính toán mô phỏng và biểu thị ở bảng 5 , bảng 6 ta thấy:

Xét tại cùng một vị trí dọc các sông Mã, sông Lạch Trường, sông Lèn độ mặn lớn nhất tại các vị trí của kịch bản biến đổi khí hậu so với kịch bản hiện trạng có xu thế tăng theo các kịch bản RCP 4.5, RCP 8.5 qua các thời kì 2016 - 2035 và 2046 - 2065. Đặc biệt một số vị trí, độ mặn có xu thế tăng rõ rệt như: trên sông Mã tại Giàng độ mặn tăng từ $0.21 \%$ (hiện trạng) [5] đến 3.62\%o (RCP4.5) và 4.24 \%o (RCP 8.5); trên sông Lạch Trường tại ngã ba Tuần độ mặn tăng từ 3.75\% (hiện trạng) [5] đến 5.78\%o (RCP4.5) và $6.30 \%$ (RCP 8.5); trên sông Lèn tại Cụ Thôn độ mặn tăng từ $0.75 \%$ (hiện trạng) [5] đến $2.71 \%$ (RCP4.5);

Xét trong cùng một kịch bản: (1) Đối với RCP 4.5, đa phần tại các vị trí dọc các sông Mã,

Lạch Trường và sông Lèn có độ mặn lớn nhất của thời kỳ 2046 - 2065 có xu thế tăng so với thời kì 2016 - 2035, tuy nhiên sự chênh lệch không lớn. Một số vị trí có xu thế tăng rõ rệt như: trên sông Mã tại Hàm Rồng có độ mặn lớn nhất trung bình thời kì 2016 - 2035 là $5.87 \%$ và 2046 - 2065 là 6.30\%; tại Giàng có độ mặn lớn nhất trung bình thời kì 2016 - 2035 là $3.62 \%$ và 2046 - 2065 là 4.10\%o. Trong khi đó trên sông Lèn tại Cụ Thôn độ mặn lớn nhất qua hai thời kì lại có xu thế giảm. (2) Đối với RCP 8.5, đa phần tại các vị trí dọc các sông Mã, Lạch Trường và sông Lèn cũng có độ mặn lớn nhất của thời kỳ 2046 2065 có xu thế tăng so với thời kì 2016 - 2035, tuy nhiên sự chênh lệch không lớn. Điều này có thể hiểu do với kịch bản biến đổi có xét đến hồ chứa với vai trò tham gia đẩy mặn nên ranh giới mặn so với kịch bản hiện trạng là không khác 
nhau nhiều.

Xét trong cùng một thời kỳ (2016 - 2035) hay (2046 - 2065) thì độ mặn lớn nhất tại các vị trí của kịch bản RCP 4.5 và $\mathrm{RCP} 8.5$ chênh lệch nhau không nhiều trên cả sông Mã, sông Lạch Trường và sông Lèn; độ mặn lớn nhất tại các vị trí dọc sông Mã lớn hơn các vị trí dọc sông Lạch Trường; độ mặn lớn nhất tại các vị trí dọc sông Lạch Trường lại lớn hơn các vị trí dọc sông Lèn. Kết quả này phần nào phù hợp bởi về mùa cạn, lưu lượng sông Mã phân lưu vào sông Lạch Trường là rất ít, dòng chảy trong sông chịu ảnh hưởng mạnh của thủy triều. Vì vậy mức độ xâm nhập mặn sẽ lớn hơn cả về độ mặn và vị trí.

\section{Kết luận}

Việc ứng dụng thành công bộ mô hình MIKE
(Mike - Nam và Mike 11) trong việc diễn toán mưa - dòng chảy và mô phỏng thủy lực, lan truyền mặn, bài báo đã nghiên cứu tính toán, phân vùng hạn - mặn vùng đồng bằng ven biển sông Mã có xét tới ảnh hưởng của hồ chứa trong điều kiện biến đổi khí hậu. Kết quả cho thấy, dưới ảnh hưởng của biến đổi khí hậu thì mối quan hệ của hạn - mặn được thể hiện rõ nét hơn, ranh giới mặn của các tiểu vùng hạn - mặn có xu thế tiến sâu vào trong sông cũng như độ mặn dọc sông tăng lên qua các thời kì (2016 - 2035) và (2045 - 2065) cũng như theo các kịch bản RCP 4.5 và $\mathrm{RCP} 8.5$. Các giải pháp cụ thể nhằm phòng chống hay khai thác để thích nghi sẽ được trình bày ở nội dung của bài báo sau.

\section{Tài liệu tham khảo}

1. Lã Thanh Hà (2014), Xây dựng mô hình dự báo xâm nhập mặn vùng hạ lưu sông Mã, sông Yên tỉnh Thanh Hóa.

2. Kịch bản biến đổi khi hậu và nước biển dâng (2016), Bộ Tài nguyên và Môi trường.

3. Thủ tướng chính phủ (2018), Quyết định số 214/QĐ - TTg ngày 13 tháng 02 năm 2018 về việc ban hành quy trình vận hành liên hồ chứa trên lưu vực sông Mã.

4. Trần Hồng Thái, Đoàn Quang Trí (2017), Application Couple Model in Saltwater Intrusion Forecasting in Estuary, LAP LAMBERT Academic Publishing.

5. Lê Thị Thường, Trương Văn Hùng (2018), Nghiên cứu tính toán phân vùng hạn - mặn vùng đồng bằng ven biển sông Mã, Tạp chí khí tượng Thủy văn, số 693,9/2018, 23-29.

6. Nguyễn Quang Trung (2012), Nghiên cứu đề xuất các giải pháp giảm thiểu ảnh huoơng của dòng chảy kiệt phuc vu sản xuất nông nghiệp, thủy sản vùng hạ du sông Cả và sông Mã, Viện Nước, Tưới tiêu và Môi trường.

7. UBND Tỉnh Thanh Hóa (2015), Báo cáo điều chỉnh bổ sung quy hoạch tổng thể phát triển kinh tế, xã hội tỉnh Thanh hóa đến năm 2020 và định hướng đến năm 2030. 


\title{
RESEARCH ON CLASSIFICATION OF DROUGHT SALT INTRUSTION IN THE MA RIVER DELTA UNDER CLIMATE CHANGE CONDITIONS
}

\author{
Le Thi Thuong ${ }^{1}$
}

${ }^{1}$ Hanoi University Natural of Resources and Environment

\begin{abstract}
The Ma river delta is heavily influenced by drought, salt intrusion, especially in the context of climate change nowadays, and the level of influence is more serious. Drought and salt intrusion often have strong relationship, but their effects are different in different zones in the same study area. Therefore, to minimize the harmful effects of drought and salinization, it is necessary to divide drought - salt intrusion into sub-areas on the basis of proposing appropriate water use solutions. The paper uses the Mike model (Mike Nam and Mike 11) to calculate the flow from the rain to the reservoir according to climate change and the hydraulic simulation of the river network in the study area in terms of drought-salinity relationship. The study has indicated three drought-salinity sub-regions corresponding to different salinity concentration. This result is significant to help managers as well as people to be proactive in changing plant and animal structure so that it is most suitable.
\end{abstract}

Keywords: Drought, saltwater intrusion, Ma river delta, climate change. 